\title{
Root characteristics of grafted peppers and their resistance to Fusarium solani
}

\author{
X. DUAN ${ }^{1}$, H.G. BI ${ }^{1}$, T. $\mathrm{LI}^{1}$, G.X. WU ${ }^{1}$, Q.M. $\mathrm{LI}^{1}$, and X.Z. AI ${ }^{1 *}$ \\ State Key Laboratory of Crop Biology / Key Laboratory of Horticultural Crop Biology and Germplasm Innovation, \\ Ministry of Agriculture / College of Horticultural Science and Engineering, Shandong Agricultural University, \\ Tai'an, Shandong, 271018, P.R. China ${ }^{1}$
}

\begin{abstract}
Root rot caused by Fusarium solani, is one of the most severe diseases in pepper (Capsicum annuum L.). Grafting has been attempted as an effective means to control the disease, but little is known about the disease resistance mechanism in grafted pepper. Therefore, we investigated the changes of biomass, cell structure, and the secondary metabolism in roots of control (non-grafted pepper) and grafted peppers using cvs. Weishi and Buyeding as rootstocks and the cv. Xinfeng 2 as a scion. After a manual inoculation, less $F$. solani invaded grafted pepper roots and consequently less serious injury to the root cell ultra-structure compared with the control was found. The roots of grafted pepper infected with $F$. solani exhibited greater biomass production and root activity than the roots of infected controls. Grafting led to an increased content of salicylic acid, benzoic acid, vanillin, lignin, and polyamines, as well as activities of phenylalanine ammonia lyase, polyphenoloxidase, and peroxidase. These results suggest that grafting improved the resistance of peppers to root rot.
\end{abstract}

Additional key words: Capsicum annuum, cell ultra-structure, root rot, secondary metabolism.

\section{Introduction}

Pepper (Capsicum annuum L.) cultivars are among the most important horticultural crops grown in many countries, where soil-borne diseases arising from continuous cropping are major problems that limit productivity. Root rot is a typical disease caused by Fusarium solani, Verticillium dahliae, and Phytophthora capsici. Root rot incidence is 10 to $30 \%$ in general (Jiang et al. 2010). Therefore, improving root rot resistance is a major scientific and economic challenge in pepper.

Grafting has been attempted as an effective means to control soil-borne diseases (Van Steekelenburg 1980, Gisbert et al. 2010) and since the fumigant methyl bromide was phased out, it has been more widely used, especially on melons and other plants of Solanaceae family (King et al. 2008). However, grafting is not as widespread in pepper plants as it is in other vegetable and fruit species (Lee et al. 2010, López-Marín et al. 2013).
Lee (1994) found that grafting improved growth and disease-resistance and therefore suggested that grafting using tolerant pepper rootstock was a promising strategy to control the problems arising from continuous cropping and soil-borne diseases. Grafted pepper has been shown to increase growth and resistance to Phytophthora blight and bacterial wilt caused by Ralstonia solanacearum (Santos and Goto 2004, Jang et al. 2012). Recently, we identified two pepper cvs. Weishi (WS) and Buyeding (BYD) that have high root rot resistance and might be suitable rootstocks.

Root rot fungi, such as $F$. solani, $V$. dahliae, and $P$. capsici, mostly invade the lenticels and wounds of plant roots. Therefore, the root growth and structural characteristics are closely associated with resistance. In a previous study, we used WS as the rootstock and identified different responses to root rot using manual

Submitted 6 December 2015, last revision 19 June 2016, accepted 1 August 2016.

Abbreviations: BYD - Buyeding; DI - disease index; PAL - phenylalanine ammonia lyase; PAs - polyamines; POD - peroxidase; PPO - polyphenoloxidase; Put - putrescine; SA - salicylic acid; Spd - spermidine; Spm - spermine; WS - Weishi; XF - Xifeng 2.

Acknowledgments: This work was supported by the Special Fund of Modern Agriculture Industrial Technology System of Shandong province in China (contract No. SDAIT-05-10).

* Corresponding author: e-mail: axz@sdau.edu.cn 
inoculation. However, we still do not know how the root structure and other characteristics change after infection with root rot pathogens and whether they are involved in the root rot resistance of grafted peppers. Therefore, in this study, we investigated the changes of the root

\section{Materials and methods}

Plants and treatments: Based on previous studies, we selected pepper (Capsicum annuum L.) cvs. WS and BYD as rootstocks and cv. Xinfeng 2 (XF) as the scion. The pepper seeds were sown in plastic pots filled with sterilized soil (one plant per pot) and grown in a greenhouse at a 14-h photoperiod, an average photon flux density of $300-500 \mu \mathrm{mol} \mathrm{m} \mathrm{m}^{-2} \mathrm{~s}^{-1}$, day/night temperatures of $25-30 / 15-20^{\circ}$, and a relative humidity of $75 \pm 5 \%$. When the rootstocks were approximately $30 \mathrm{~cm}$ tall (with 5 - 6 leaves), the pepper seedlings were grafted using the cleft grafting method (Lee 1994). The grafted combinations (cultivar/rootstock) were labelled XF/WS and $\mathrm{XF} / \mathrm{BYD}$. The rootstock (WS and BYD) seeds are smaller and the seeding stage is longer than those of $\mathrm{XF}$, so $\mathrm{XF}$ were sown 2 weeks later than the rootstock plants, and the scion and rootstock were of the same species (XF/XF, control) to obtain plants with a similar biomass to the grafted plants at transplantation time (5 - 6 leaf stage).

One month after grafting, the grafted and control pepper plants were inoculated with Fusarium solani (Mart.) App. et Wollenw isolated from a pepper field in Zaozhuang, Shandong, China by the immersion method. The suspension solution was prepared by culturing the pathogen in Martin medium (Jiang et al. 2010) and diluting with distilled water to a concentration of $5 \times 10^{6}$ conidia $\mathrm{cm}^{-3}$. The treated plants were transplanted into plastic pots filled with soil + Vermiculite. There were 3 replicates per treatment and 50 seedlings per replicate. The roots were sampled for analysis on $0,5,10$, and $15 \mathrm{~d}$ after inoculation.

Investigation of disease incidence and disease index: The disease incidence and disease index of root rot was measured $7 \mathrm{~d}$ after inoculation. The presence of root rot was visually rated according to the disease classification assessed on a 0 to 5 degree scale that reflected the condition of the injured plants $(0$ - no disease; 1 - less than $10 \%$ roots changed colour, no leaves wilted; $2-10$ to $30 \%$ of the roots were brown, and some leaves started to wilt; 3 - 30 to $50 \%$ roots were brown, and plants were distinctly withered; 4 - more than $50 \%$ of roots were brown, and most leaves withered, except for the heart leaves; 5 - plant dead). The disease index (DI) was calculated according to formula: DI $[\%]=\frac{\Sigma \text { di } \times \mathrm{Ii}}{\mathrm{L} \times 5} \times 100$, (where di is disease degree, Ii is the number of injured plants at each degree, $\mathrm{L}$ is the total number of samples and 5 is the highest injury degree). biomass, cell ultra-structure, and secondary metabolism in grafted or non-grafted peppers before and after inoculation. The results should provide basis for future research on improving the disease resistance of peppers and other horticultural crops.

Determination of root biomass, activity, and absorbing area: The root length, root volume, root surface area, and number of root tips and root forks of grafted and non-grafted pepper plants were determined with a root analyzer $(J 181 A$, Shanghai, China) and analysis software (WinRHIZO, USA) on 0,5 , and $15 \mathrm{~d}$ after inoculation. The root mass was measured with an electronic balance, and the root activity was assessed by the triphenyltetrazolium chloride (TTC) method (Ruf and Brunner 2003). The root absorbing area and the active absorbing area were measured by methyl-blue absorption method of Zhao et al. (2002).

Detection of root cell ultra-structure: Before and after inoculation, the root segments $(1-2 \mathrm{~mm})$ of grafted and control pepper roots were fixed in $3.5 \%(\mathrm{~m} / \mathrm{v})$ glutaraldehyde and $1 \%(\mathrm{~m} / \mathrm{v})$ osmic acid for $2 \mathrm{~h}$. After fixation and dehydration in an ethanol series, the root samples were embedded in Epon 812 resin and sliced using an $L K B-5$ (Stockholm, Sweden) ultrathin slicer. The ultrathin sections were stained with uranyl acetate followed by lead citrate and examined with a JEM-1200 EX (Jeol, Tokyo, Japan) transmission electron microscope.

Measurement of secondary metabolism substances and activities of related enzymes

The phenolic acid content was analyzed via HPLC (Waters-510 HPLC, Waters-2487 ultraviolet detector, Waters, USA) according to Proestos et al. (2005). The lignin content in the pepper roots was determined as described by Iiyama and Wallis (1990) with several modifications according to Syros et al. (2004). Polyamines were extracted according to Sharma and Rajam (1995) with several modifications done by Wei et al. (2009). The phenylalnineammonia lyase (PAL) activity was determined according to Yuan et al. (2001). The polyphenol oxidase (PPO) activity was assayed as described by Rao and Deosthale (1987). The peroxidase (POD) activity was determined by the guaiacol method according to Omran (1980).

Statistical analysis: The data are presented as the mean \pm standard deviation (SD) of three replicates. Analysis of variance $(A N O V A)$ was performed using DPS software. Duncan's multiple range test (DMRT) was applied to analyze differences between measured parameters. 


\section{Results}

Five days after inoculation, no diseased plants were found in XF/WS. However, the disease incidence in XF/BYD and XF/XF (control) was 26.7 and $43.0 \%$, and the disease index was 11.7 and $23.3 \%$, respectively (Table 1). Afterward, the disease incidence and disease index in grafted and control pepper plants gradually increased with time, but the extent of increase varied. Compared to the control, the disease incidence and disease index were significantly lower in grafted plants $(P<0.05)$. Fifteen days after inoculation, the disease incidence and disease index of the control plants increased to 88.7 and $75.7 \%$, while those of the XF/WS plants only to 23.3 and $19.0 \%$, and of XF/BYD to 54.0 and $28.3 \%$, respectively. These data suggest that grafting improved the root rot resistance of pepper.

Before inoculation, XF/WS (Fig. $1 A$ ) and XF/BYD (Fig. $1 B$ ) plants had more fine roots and root hairs than the control plants (Fig. 1C). After infection with $F$. solani, the roots of grafted and the control pepper were damaged, as shown by the decrease in number of lateral roots and root hairs. However, less damage was observed in grafted plants compared with control plants, especially in XF/WS (Fig. 1).

The fresh mass, total length, volume, surface area, and number of tips and forks of XF/WS and XF/BYD roots were significantly greater than those of the control

Table 1 Disease incidence [\%] and disease index [\%] of root rot in grafted (XF/WS or XF/BYD) and control (XF/XF) peppers. Means \pm SDs, $n=3$, different letters indicate that means are significantly different $(P<0.05)$.

\begin{tabular}{|c|c|c|c|c|c|c|}
\hline Treatments & $\begin{array}{l}5 \mathrm{~d} \text { after inoculation } \\
\text { disease incidence }\end{array}$ & disease index & $\begin{array}{l}10 \mathrm{~d} \text { after inoculatio } \\
\text { disease incidence }\end{array}$ & $\begin{array}{l}\text { on } \\
\text { disease index }\end{array}$ & $\begin{array}{l}15 \mathrm{~d} \text { after inoculatio } \\
\text { disease incidence }\end{array}$ & $\begin{array}{l}\text { on } \\
\text { disease index }\end{array}$ \\
\hline XF/WS & $0 \mathrm{c}$ & $0 \mathrm{c}$ & $10.7 \pm 1.2 \mathrm{c}$ & $8.7 \pm 0.6 \mathrm{c}$ & $23.3 \pm 1.5 \mathrm{c}$ & $19.0 \pm 0.1 \mathrm{c}$ \\
\hline XF/BYD & $26.7 \pm 1.5 \mathrm{~b}$ & $11.7 \pm 0.6 \mathrm{~b}$ & $32.3 \pm 1.5 \mathrm{~b}$ & $19.3 \pm 1.2 \mathrm{~b}$ & $54.0 \pm 2.0 \mathrm{~b}$ & $28.3 \pm 1.5 \mathrm{~b}$ \\
\hline $\mathrm{XF} / \mathrm{XF}$ & $43.0 \pm 2.0 \mathrm{a}$ & $23.3 \pm 0.6 \mathrm{a}$ & $60.3 \pm 2.1 \mathrm{a}$ & $46.7 \pm 2.5 \mathrm{a}$ & $88.7 \pm 1.5 \mathrm{a}$ & $75.7 \pm 3.1 \mathrm{a}$ \\
\hline
\end{tabular}

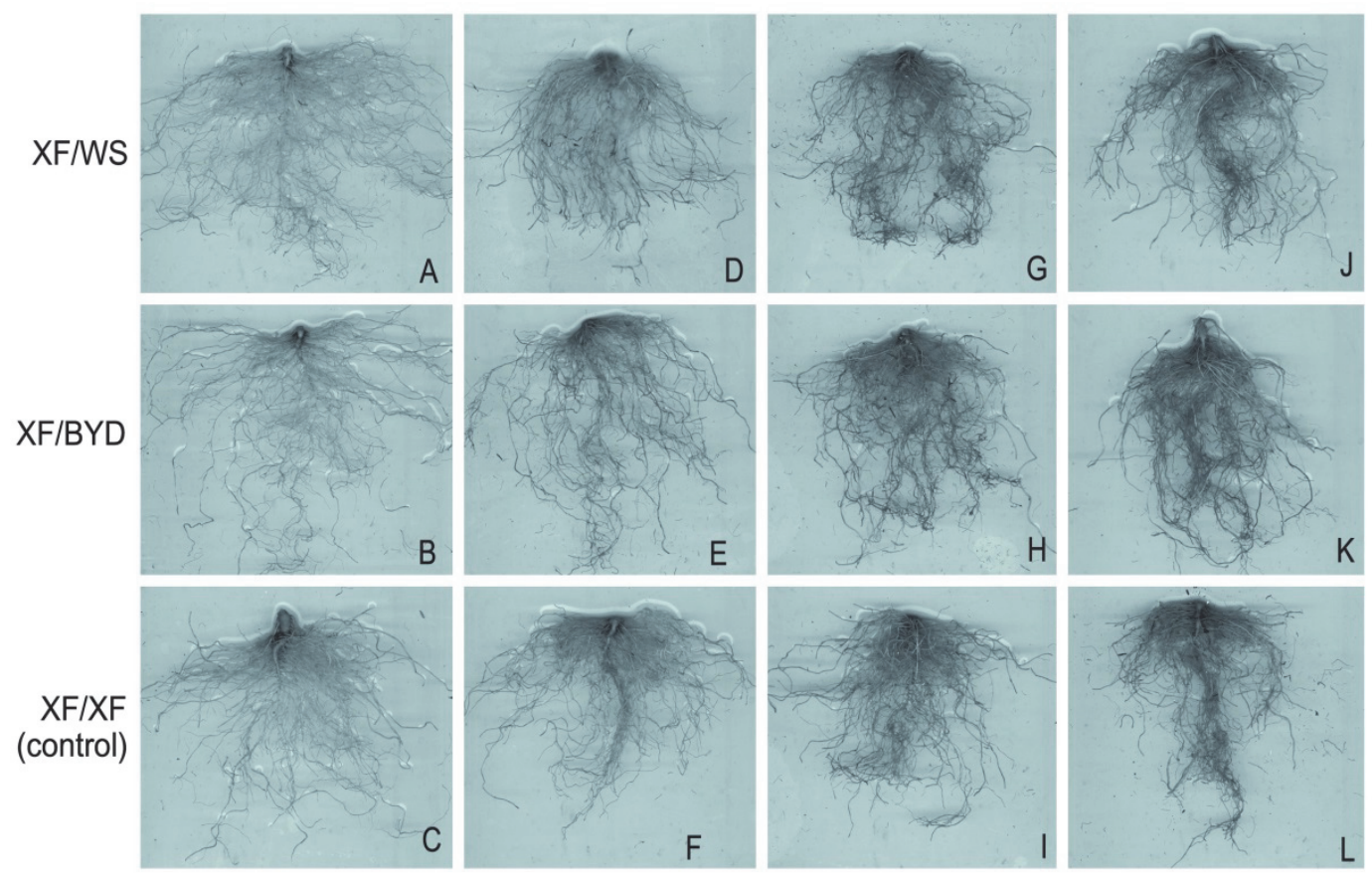

Fig. 1. Roots of grafted (XF/WS, XF/BYD) and control (XF/XF) peppers before and after inoculation: $A, B, C$ - before inoculation, $D, E, F-5 \mathrm{~d}$ after inoculation, $G, H, I-10 \mathrm{~d}$ after inoculation, $J, K, L-15 \mathrm{~d}$ after inoculation.

before inoculation $(P<0.05)$. During the experiment, the above parameters all decreased, but XF/WS had the highest values and the control the lowest values from beginning to end. Fifteen days after inoculation, the root mass, length, volume, surface area, and number of tips and forks of XF/WS were 58.5, 52.7, 62.9, 55.3, 39.3 and $29.8 \%$ higher than those of the control, respectively, and the values for XF/BYD were 31.7, 37.9, 16.9, 44.4, 21.1, and $14.6 \%$ higher, respectively, compared with the control (Fig. 2). 

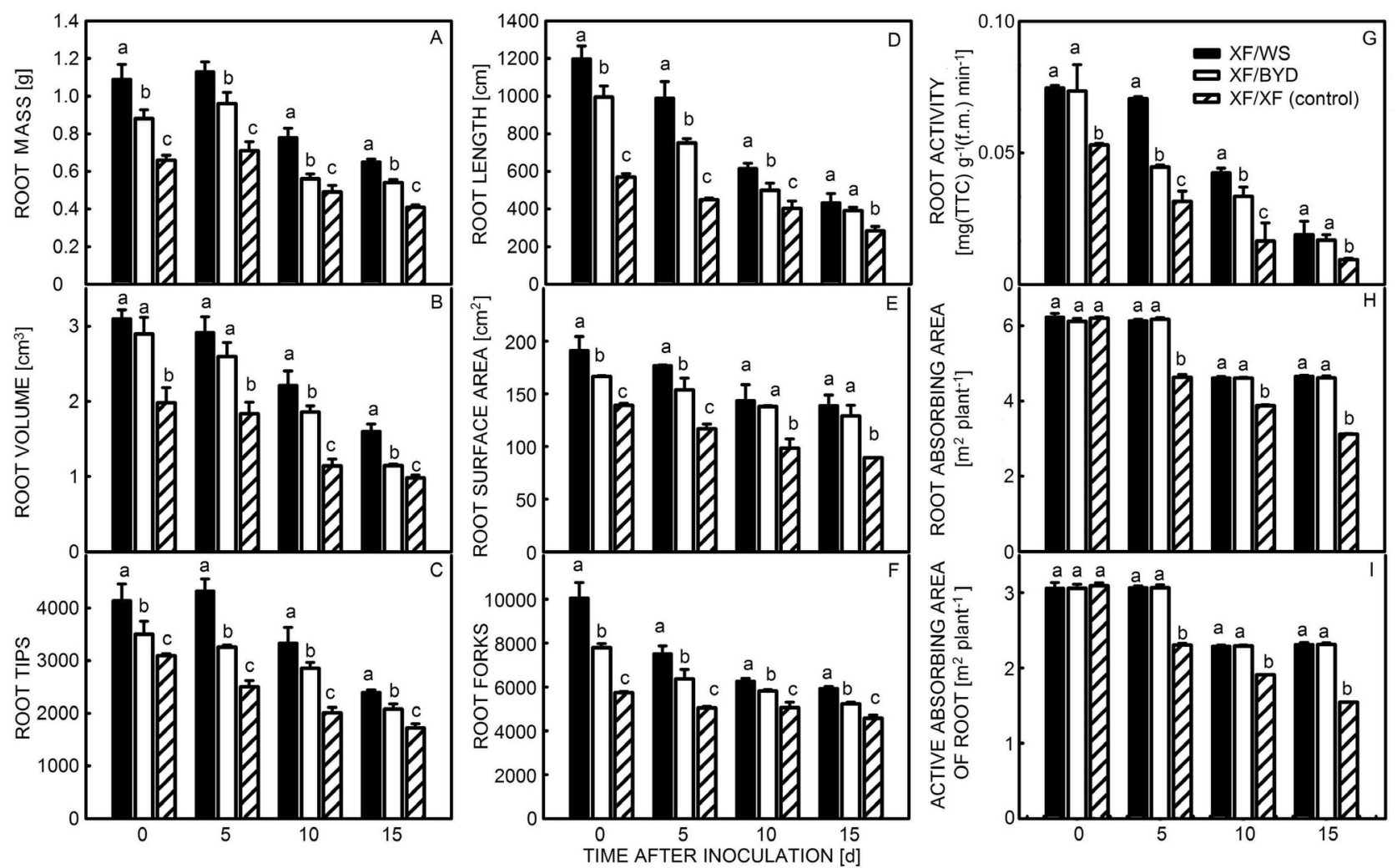

Fig. 2. The root growth, activity, and absorbing area of grafted (XF/WS and XF/BYD) and control (XF/XF) peppers: root fresh mass $(A)$, root volume $(B)$, number of root tips $(C)$, root total length $(D)$, root surface area $(E)$, number of root forks $(F)$, root activity $(G)$, root absorbing area $(H)$, and active absorbing area of root $(I)$. Means \pm SDs, $n=3$, different letters indicate that means are significantly different $(P<0.05)$.

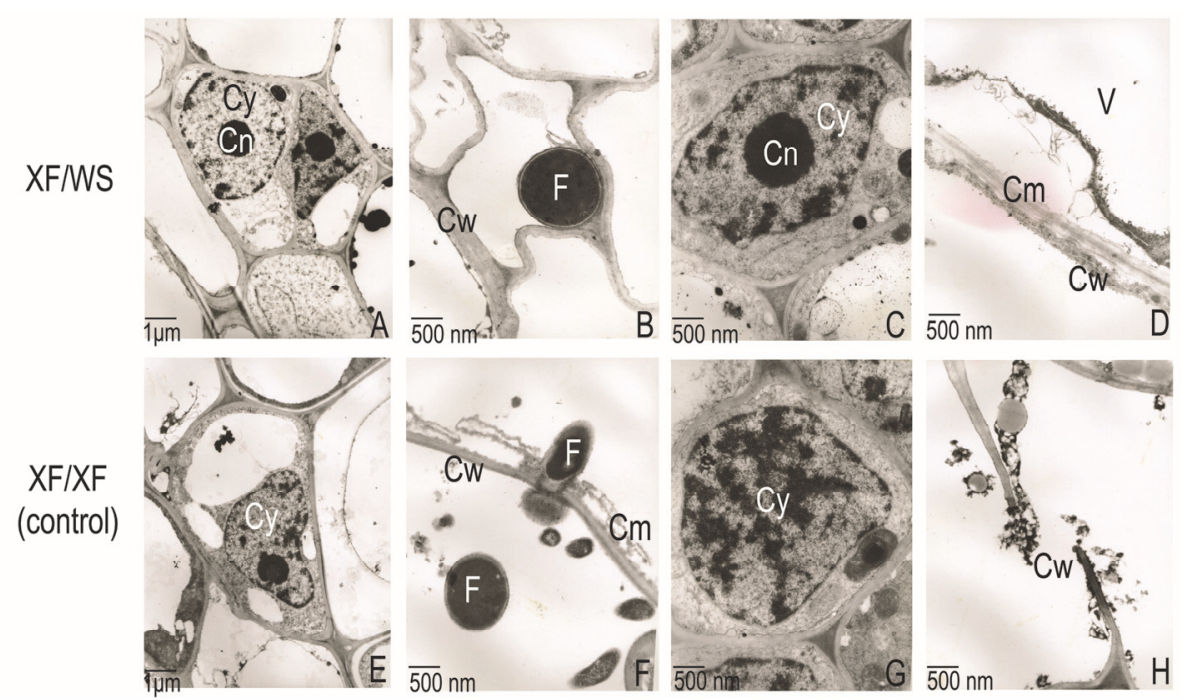

Fig. 3. The cell ultrastructure of roots of in grafted (XF/WS) and control (XF/XF) pepper plants: $A$ - uninfected XF/WS; $B, C, D$ $\mathrm{XF} / \mathrm{WS}$ infected by $F$. solani for $5 \mathrm{~d} ; E$ - uninfected XF/XF; $F, G, H-\mathrm{XF} / \mathrm{XF}$ infected by $F$. solani for $5 \mathrm{~d}$. $\mathrm{F}$ - fungus, Cm - cell membrane, $\mathrm{Cn}$ - cell nucleus, $\mathrm{Cy}$ - cytoplasm, $\mathrm{Cw}$ - cell wall, $\mathrm{V}$ - vacuole.

Grafting led to a remarkable increase in root activity and showed no significant difference between XF/WS and XF/BYD before inoculation (Fig. 2G). The root activities of grafted and control plants declined gradually following inoculation, but the decline was the lowest in $\mathrm{XF} / \mathrm{WS}$ and the highest in control $(P<0.05)$. Therefore, a 
higher root activity in the grafted pepper plants probably played an important role in the enhancement of root rot disease resistance.

Before inoculation, no differences were observed in the absorbing area (Fig. $2 H$ ) and the active absorbing area (Fig. 2I) of roots between grafted and control plants. Five days after inoculation, the absorbing area and active absorbing area significantly decreased in the control plants, but no change was detected in the grafted plants. Afterward, the root absorbing area and active absorbing area decreased gradually in grafted and the control plants, but the decrease were remarkably less in grafted plants than in control plants $(P<0.05)$.

To further evaluate the relationship between the root characteristics and the root rot resistance in grafted peppers, we determined the changes in the root ultrastructure of grafted XF/WS and control plants $5 \mathrm{~d}$ after inoculation (Fig. 3). The results showed that invading conidia of $F$. solani were observed in both XF/WS and control root cells (Fig. $3 B, F$ ), but the density was significantly lower in grafted roots than in control roots. The control root cells were seriously damaged, as evidenced by membrane injury, a disaggregation of the nucleus and cytoplasm (Fig. $3 G$ ), and a rupture of the cell wall (Fig. 3H). However, the ultra-structure of the grafted pepper roots was mostly normal, except for some plasma membrane injury (Fig. 3C) and plasmolysis (Fig. 3D).

Before inoculation, 13 phenolic acids were isolated from control pepper roots (Table 2). Among them, chlorogenic acid was present in the highest amount, followed by gallic acid, caffeic acid, and benzoic acid (51.52 $\left.\mu \mathrm{g} \mathrm{g}^{-1} \mathrm{DW}\right)$. The same phenolic acids were isolated from XF/WS roots. Gallic acid was present in the highest amount in XF/WS roots, followed by chlorogenic acid, caffeic acid, and benzoic acid, with others in lower amounts. In comparison with control, grafted pepper roots had a higher content of caffeic acid, benzoic acid, phloretin, salicylic acid, phlorizin, and P-hydroxybenzoic acid, but lower content of chlorogenic acid, gallic acid, cinnamic acid, and ferulic acid. No differences were observed in content of vanillin, catechinic acid and quercetin. After inoculation, gallic, chlorogenic, and catechinic acid decreased gradually in both XF/WS and the control roots, and many others increased during the first 5 or $10 \mathrm{~d}$ after infection but subsequently decreased, except for salicylic acid, which increased with time of infection. XF/WS roots showed a higher content of salicylic acid, benzoic acid, and vanillin but a lower content of gallic acid, chlorogenic acid, and quercetin, compared with control roots.

After inoculation, the lignin content increased gradually with time, but the extent of increase was remarkably less in XF/WS and XF/BYD than in the control $(P<0.05)$ (Fig. $4 A)$; however, $15 \mathrm{~d}$ after inoculation, the lignin content in XF/WS and XF/BYD increased by 105.9 and $71.5 \%$, respectively, but in the control only by $40.9 \%$.

Before inoculation, $\mathrm{XF} / \mathrm{WS}$ and $\mathrm{XF} / \mathrm{BYD}$ roots showed a higher putrescine (Put) content $(P<0.05)$ compared with the control roots, but no distinct difference was found in spermidine (Spd) content (Fig. 4B,C). The XF/BYD roots revealed higher spermine (Spm) content than the control $(P<0.05)$ (Fig. 4D), whereas XF/WS had a similar Spm content to the control. After inoculation, Put, Spd, and Spm content firstly increased and then decreased, but was highest in XF/WS and lowest in the control $(P<0.05)$.

The enzymes closely associated with plant disease resistance are PAL, PPO, and POD. The PAL activity in roots was dramatically elevated after infection $F$. solani for $10 \mathrm{~d}$, being 1.17 - 1.83-fold higher than before inoculation, but subsequently declined. Compared with the control, the grafted roots showed higher PAL activity $(P<0.05)$ throughout the experiment (Fig. 4E). PPO

Table 2. Changes of phenolic acids $\left[\mu \mathrm{g} \mathrm{g}^{-1}(\mathrm{~d} . \mathrm{m}).\right]$ in roots of grafted (XF/WS) and control (XF/XF) peppers before and after inoculation. Means $\pm \mathrm{SDs}, n=3$, different letters indicate that means are significantly different $(P<0.05)$.

\begin{tabular}{|c|c|c|c|c|c|c|c|c|}
\hline \multirow[t]{2}{*}{ Phenolic compounds } & \multicolumn{2}{|c|}{ Before inoculation } & \multicolumn{2}{|c|}{$5 \mathrm{~d}$ after inoculation } & \multicolumn{2}{|c|}{$10 \mathrm{~d}$ after inoculation } & \multicolumn{2}{|c|}{$15 \mathrm{~d}$ after inoculation } \\
\hline & $\mathrm{XF} / \mathrm{WS}$ & $\mathrm{XF} / \mathrm{XF}$ & $\mathrm{XF} / \mathrm{WS}$ & $\mathrm{XF} / \mathrm{XF}$ & $\mathrm{XF} / \mathrm{WS}$ & $\mathrm{XF} / \mathrm{XF}$ & $\mathrm{XF} / \mathrm{WS}$ & $\mathrm{XF} / \mathrm{XF}$ \\
\hline Gallic acid & $224.5 \mathrm{~b}$ & $294.3 \mathrm{a}$ & $179.0 \mathrm{~b}$ & $282.5 \mathrm{a}$ & $153.2 \mathrm{~b}$ & 277.9 a & $8.0 \mathrm{~b}$ & $254.7 \mathrm{a}$ \\
\hline Chlorogenic acid & $122.4 \mathrm{~b}$ & $334.0 \mathrm{a}$ & $74.7 \mathrm{a}$ & $37.3 \mathrm{~b}$ & $56.7 \mathrm{a}$ & $37.3 \mathrm{~b}$ & $45.8 \mathrm{a}$ & $32.9 \mathrm{~b}$ \\
\hline$P$-hydroxybenzoic acid & $24.2 \mathrm{a}$ & $14.1 \mathrm{~b}$ & $24.4 \mathrm{a}$ & $27.4 \mathrm{a}$ & $22.6 \mathrm{a}$ & $26.0 \mathrm{a}$ & $20.7 \mathrm{a}$ & $22.1 \mathrm{a}$ \\
\hline Ferulic acid & $20.0 \mathrm{~b}$ & $30.9 \mathrm{a}$ & $36.6 \mathrm{a}$ & $41.0 \mathrm{a}$ & $62.6 \mathrm{a}$ & $33.7 \mathrm{~b}$ & $18.6 \mathrm{~b}$ & $33.8 \mathrm{a}$ \\
\hline Benzoic acid & $68.3 \mathrm{a}$ & $51.5 \mathrm{~b}$ & $162.7 \mathrm{a}$ & $72.3 \mathrm{~b}$ & $134.6 \mathrm{a}$ & $57.0 \mathrm{~b}$ & $118.9 \mathrm{a}$ & $59.8 \mathrm{~b}$ \\
\hline Cinnamic acid & $7.5 \mathrm{~b}$ & $18.3 \mathrm{a}$ & $19.3 \mathrm{~b}$ & $26.4 \mathrm{a}$ & $21.9 \mathrm{a}$ & $23.2 \mathrm{a}$ & $20.4 \mathrm{a}$ & $8.7 \mathrm{~b}$ \\
\hline Vanillin & $8.4 \mathrm{a}$ & $7.2 \mathrm{a}$ & $39.0 \mathrm{a}$ & $10.8 \mathrm{~b}$ & $15.7 \mathrm{a}$ & $5.5 \mathrm{~b}$ & $9.3 \mathrm{a}$ & $5.5 \mathrm{~b}$ \\
\hline Catechin & $32.2 \mathrm{a}$ & $35.6 \mathrm{a}$ & $21.4 \mathrm{~b}$ & $34.8 \mathrm{a}$ & $19.0 \mathrm{a}$ & $11.5 \mathrm{~b}$ & $13.1 \mathrm{a}$ & $8.3 \mathrm{~b}$ \\
\hline Caffeic acid & $91.8 \mathrm{a}$ & $76.1 \mathrm{~b}$ & $63.2 \mathrm{~b}$ & 299.9 a & $60.5 \mathrm{~b}$ & $86.4 \mathrm{a}$ & $58.4 \mathrm{a}$ & $25.3 \mathrm{~b}$ \\
\hline Phlorizin & $33.3 \mathrm{a}$ & $21.7 \mathrm{~b}$ & $11.6 \mathrm{~b}$ & $27.5 \mathrm{a}$ & $45.7 \mathrm{~b}$ & $78.4 \mathrm{a}$ & $92.7 \mathrm{a}$ & $18.3 \mathrm{~b}$ \\
\hline Salicylic acid & $36.5 \mathrm{a}$ & $6.6 \mathrm{~b}$ & $46.9 \mathrm{a}$ & $31.6 \mathrm{~b}$ & $87.0 \mathrm{a}$ & $36.5 \mathrm{~b}$ & $91.1 \mathrm{a}$ & $9.1 \mathrm{~b}$ \\
\hline Quercetin & $26.5 \mathrm{a}$ & $29.9 \mathrm{a}$ & $4.8 \mathrm{~b}$ & $34.0 \mathrm{a}$ & $11.4 \mathrm{~b}$ & $102.5 \mathrm{a}$ & $14.6 \mathrm{~b}$ & $60.4 \mathrm{a}$ \\
\hline Phloretin & $38.4 \mathrm{a}$ & $29.2 \mathrm{~b}$ & $14.3 \mathrm{~b}$ & $22.7 \mathrm{a}$ & $15.5 \mathrm{~b}$ & $31.3 \mathrm{a}$ & $26.6 \mathrm{a}$ & $24.5 \mathrm{a}$ \\
\hline
\end{tabular}


activity was significantly increased by inoculation in both grafted and the control roots (Fig. $4 F$ ) and $15 \mathrm{~d}$ after inoculation, the PPO activities in XF/WS and XF/BYD were 78.5 and $33.1 \%$ higher than in the control, respectively. POD activity increased significantly during the first $5 \mathrm{~d}$ following inoculation but subsequently decreased (Fig. 4G). The grafted roots showed an obviously higher POD activity than the control roots $(P<0.05)$.

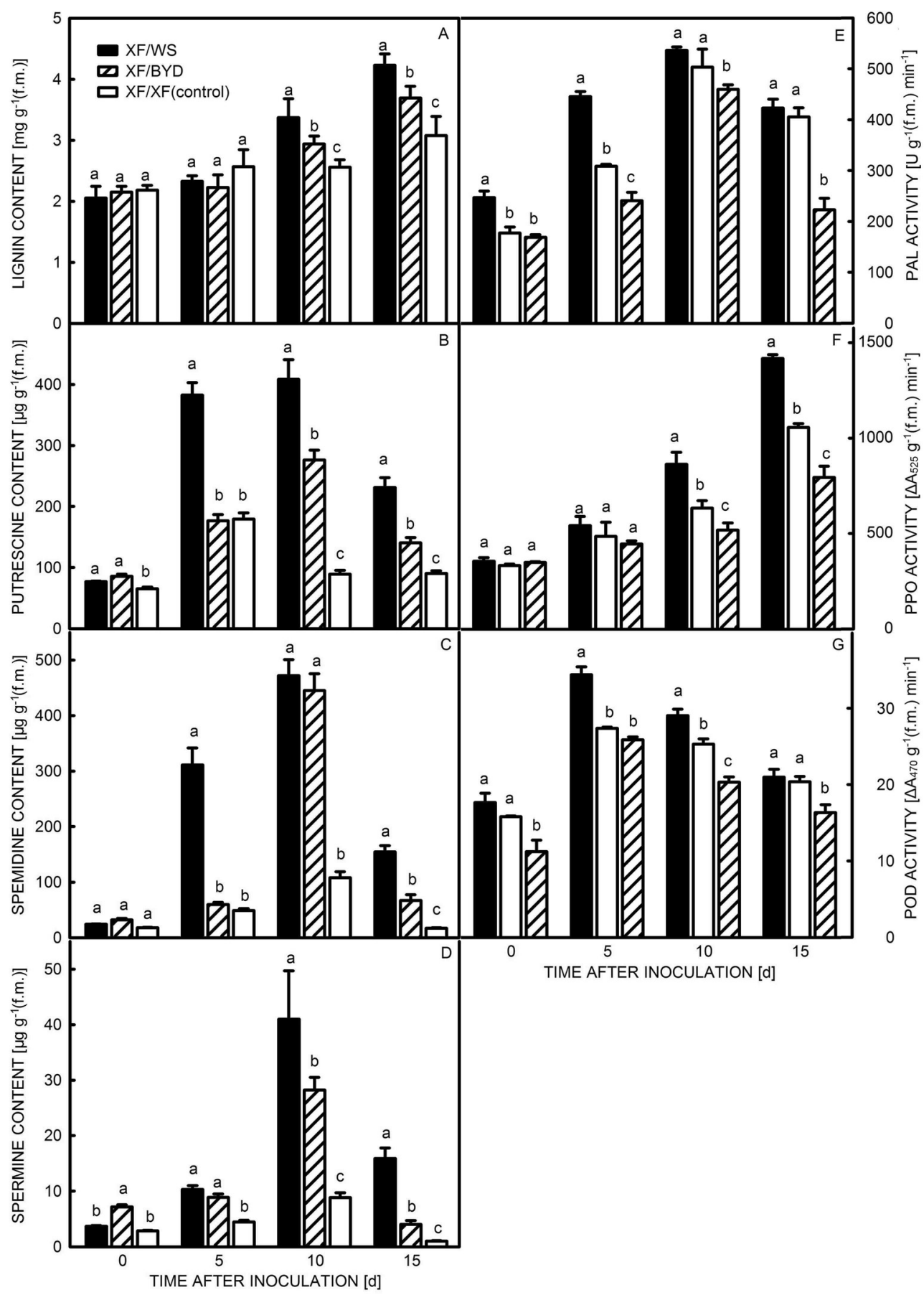

Fig. 4. Content of secondary metabolites and activities of related enzymes in roots of grafted (XF/WS and XF/BYD) and control $(\mathrm{XF} / \mathrm{XF})$ peppers: lignin $(A)$, putrescine $(B)$, spermidine $(C)$, spermine $(D)$, PAL $(E)$, PPO $(F)$, and POD $(G)$. Means $\pm \mathrm{SDs}, n=3$, different letters indicate that means are significantly different $(P<0.05)$. 


\section{Discussion}

Soilborne pathogens often infect and damage plant roots, and, as a result, plant nutrient and water uptake can be negatively affected. Therefore, root system size and vigor may be associated with resistance to soilborne diseases. In this study, we demonstrate that the root rot resistance can be improved by grafting robust rootstocks, based on a decrease in disease incidence, disease index, and the quantity of $F$. solani that invaded pepper roots. We found that $F$. solani invasion significantly reduced growth in both grafted and non-grafted pepper roots. However, the grafted peppers had remarkably more root hairs, a greater root volume and absorption area, and higher root activity (Figs. 1, 2). Therefore, the grafted pepper roots, which were less seriously injured by $F$. solani, retained stronger absorption ability and maintained higher physiological functionality during the experiment. This is an important cause of the enhancement of disease resistance in grafted peppers.

Plant secondary metabolism encompasses all physiological and biochemical facets of "secondary products" including the functional and evolutionary aspects (Iriti and Faoro 2009). Phenolic acids are important secondary metabolites common in higher plants and exhibit strong allelopathy (Classen et al. 1990). They are involved in defense against biotic and abiotic stresses and contribute significantly to antioxidant activity in plant tissues (Ferrat et al. 2003, Pourcel et al. 2007, Bharti et al. 2013). Anwar et al. (1995) reported that the composition of phenolic acids in maize and sorghum leaves change after the Peronosclerospora sorghi invasion. Among the compounds detected in our study, XF/WS roots showed a significant increase in salicylic acid, benzoic acid, and vanillin over the control roots both before and after inoculation, which suggested that these compounds played a major role in improving the disease resistance of grafted pepper plants.

Enhanced activities of secondary metabolism-related enzymes in plants are usually caused by pathogen

\section{References}

Anwar, M., Majumder S., Shetty H.: Changes in phenolic acids in sorghum and maize leaves infected with Peronosclerospora sorghi. - Indian Phytopathol. 48: 21-26, 1995.

Bharti, N., Deepti Yadav, D., Barnawal, D., Maji, D., Kalra, A.: Exiguobacterium oxidotolerans, a halotolerant plant growth promoting rhizobacteria, improves yield and content of secondary metabolites in Bacopa monnieri (L.) Pennell under primary and secondary salt stress. - World J. Microbiol. Biotechnol. 29: 379-387, 2013.

Classen, D., Arnason, J.T., Serratos, J.A., Lambert, J.D.H., Nozzolillo, C., Philogène, B.J.R.: Correlation of phenolic acid content of maize to resistance to Sitophilus zeamais, the maize weevil, in CIMMYT'S collections. - J. chem. invasion. The PAL is a key enzyme in the phenylpropanoid pathway. Thus, the formation of lignin, sinapic acid esters, and flavonoids all depend on PAL activity (Olsen et al. 2008). Yin et al. (2013) found that PAL activity, consistent with transcripts of $P A L$ gene, is significantly induced in apples by Diplocarpon mali inoculation, and inoculated plants of a resistant cultivar have greater PAL activity than those of the the susceptible cultivar. The PPO is involved in the oxidation of polyphenols into quinones (antimicrobial compounds) and the lignification of plant cells during microbial invasion. Previous studies indicated that PPO activity is related to the extent of disease resistance demonstrated by wheat heads following inoculation with Fusarium graminearum conidia (Mohammadi and Kazemi 2002). Enhanced POD activity has been also correlated with improved disease resistance in wheat (Mohammadi and Kazemi 2002) and apple (Yin et al. 2013). Lignins are aromatic compounds that are deposited in the cell wall and play an important role in preventing pathogen infection. Considering the overall results of this study, we noticed that PAL, PPO, and POD activities increased in both grafted and non-grafted peppers after inoculation, and lignin content increased with an increase in those enzyme activities. These results indicated that infected plants accelerated secondary metabolism and formed more phenolic acids and lignin. Moreover, higher PAL, PPO, and POD activities were observed in grafted plants than in control plants, suggesting that they improves the effectiveness of the cell wall barrier to prevent or retard the spread of a pathogen. This finding might explain why grafted plants exhibited an increase in lignin content especially at a later time after inoculation compared to control plants which contributed to the inhibition of the $F$. solani conidial invasion. Therefore, we suggest that PAL, PPO, and POD activities in pepper roots are positively correlated with the degree of resistance against F. solani.
Ecol. 16: 301-315, 1990.

Ferrat, L., Pergent-Martini, C., Roméo, M.: Assessment of the use of biomarkers in aquatic plants for the evaluation of environmental quality: application to seagrasses. - Aquat. Toxicol. 65: 187-204, 2003.

Gisbert, C., Sánchez-Torres, P., Raigón, M.D., Nuez, F.: Phytophthora capsici resistance evaluation in pepper hybrids: agronomic performanceand fruit quality of pepper grafted plants. - J. Food Agr. Environ. 8: 116-121, 2010.

Iiyama, K., Wallis, A.F.A.: Determination of lignin in herbaceous plants by an improved acetyl bromide procedure. - J. Sci. Food Agr. 51: 145-161, 1990.

Iriti, M., Faoro, F.: Ozone-induced changes in plant secondary metabolism. - climate change and crops. - Environ. Sci. 
Engin. 245-268, 2009.

Jang, Y., Yang, E., Cho, M., Um, Y., Ko, K., Chun, C.: Effect of grafting on growth and incidence of phytophthora blight and bacterial wilt of pepper (Capsicum annuum L.). - Hort. Environ. Biotechnol. 53: 9-19, 2012.

Jiang, F., Liu, Y., Ai, X., Zheng, N., Wang, H.: [Study on relationship among microorganism, enzymes' activity in rhizosphere soil and root rot resistance of grafted capsicum.] - Scientia agr. sin. 43: 3367-3374, 2010. [In Chin.]

King, S.R., Davis, A.R., Liu, W., Levi, A.: Grafting for disease resistance. - HortScience 43: 1673-1676, 2008.

Lee, J.M.: Cultivation of grafted vegetables. I. Current status, grafting methods, and benefits. - HortScience 29: 235-239, 1994.

Lee, J.M., Kubota, C., Tsaoc, S.J., Bied, Z., Echevarriae, P. H., Morraf, L., Oda, M.: Current status of vegetable grafting: diffusion, grafting techniques, automation. - Sci. Hort. 127: 93-105, 2010.

López-Marín, J., Gonzáleza, A., Pérez-Alfoceab, F., EgeaGilabertc, C., Fernández, J. A.: Grafting is an efficient alternative to shading screens to alleviate thermal stress in greenhouse-grown sweet pepper. - Sci. Hort. 149: 39-46, 2013.

Mohammadi, M., Kazemi, H.: Changes in peroxidase and polyphenol oxidase activities in susceptible and resistant wheat heads inoculated with Fusarium graminearum and induced resistance. - Plant Sci. 162: 491-498, 2002.

Olsen, K.M., Lea,U.S., Slimestad, R., Verheul, M., Lillo, C.: Differential expression of four Arabidopsis PAL genes; $P A L 1$ and $P A L 2$ have functional specialization in abiotic environmental-triggered flavonoid synthesis. - J. Plant Physiol. 165: 1491-1499, 2008.

Omran, R.G.: Peroxide levels and the activities of catalase, peroxidase, and indoleacetic acid oxidase during and after chilling cucumber seedlings. - Plant Physiol. 65: 407-408, 1980 .

Pourcel, L., Routaboul, J.-M., Cheynier, V., Lepiniec, L., Debeaujon, I.: Flavonoid oxidation in plants: from biochemical properties to physiological functions. - Trends Plant Sci. 12: 29-36, 2007.
Proestos, C., Chorianopoulos, N., Nychas, G.-J.E., Komaitis, M.: RP-HPLC analysis of the phenolic compounds of plant extracts investigation of their antioxidant capacity and antimicrobial activity. - J. Agr. Food Chem. 53: 1190-1195, 2005.

Rao, P.U., Deosthale Y. G.: Polyphenoloxidase activity in germinated legume seeds. - J. Food Sci. 52: 1549-1551, 1987.

Ruf, M., Brunner, I.: Vitality of tree fine roots: reevaluation of the tetrazolium test. - Tree Physiol. 23: 257-263, 2003.

Santos, H., Goto, R.: Sweet pepper grafting to control Phytophthora blight under protected cultivation. Horticult. brasil. 22: 45-49, 2004.

Sharma, P., Rajam, M.: Spatial and temporal changes in endogenous polyamine levels associated with somatic embryogenesis from different hypocotyl segments of eggplant (Solanum melongena L.). - J. Plant Physiol. 146: 658-664, 1995.

Syros, T., Yupsanis, T., Zafiriadis, H., Economou, A.: Activity and isoforms of peroxidases, lignin and anatomy, during adventitious rooting in cuttings of Ebenus cretica L. - J. Plant Physiol. 161: 69-77, 2004.

Van Steekelenburg, N.A.M.: Phytophthora root rot of sweet pepper. - Neth. J. Plant Pathol. 86: 259-264, 1980.

Wei, G.P., Yang, L.F., Zhu, Y.L., Chen, G.: Changes in oxidative damage, antioxidant enzyme activities and polyamine contents in leaves of grafted and non-grafted eggplant seedlings under stress by excess of calcium nitrate. - Sci. Hort. 120: 443-451, 2009.

Yin, L., Zou, Y., Ke, X., Liang, D., Du, X., Zhao,Y., Zhang, Q., Ma, F.: Phenolic responses of resistant and susceptible Malus plants induced by Diplocarpon mali. - Sci. Hort. 164: 17-23, 2013.

Yuan, Y.J., Li, C., Hu, Z.D., Wu, J.C.: Signal transduction pathway for oxidative burst and taxol production in suspension cultures of Taxus chinensis var. Mairei induced by oligosaccharide from Fusarium oxysprum. - Enzyme Microbial Technol. 29: 372-379, 2001.

Zhao, S., Shi, G., Dong, X. (ed.) : Plant Physiology Experiment Instruction. - Agricultural Science and Technology Publishing House, Beijing 2002. 